\title{
Hardware design of magnetically isolated gate driver using insulated gate bipolar transistor (IGBT)
}

\begin{abstract}
This paper presents the hardware design of compact H-bridge magnetically isolated gate driver using Insulated Gate Bipolar Transistor (IGBT) as power device. The new Gate Driver (GD) circuit is tested experimentally with various switching frequency to observe the performance of the circuit. The compact H-Bridge is design using Proteus in one circuit board with two layers Printed Circuit Board (PCB). Switching transients of the IGBT is analyzed based on the capabilities of the GD circuit.
\end{abstract}

Keyword: H-bridge; Insulated gate bipolar transistor (IGBT); Gate driver (GD); Printed circuit board (PCB); Rise time; Fall time 